Research Article

\title{
Impact System Dynamic Characteristics of Hydraulic Rock Drill Based on an Overlapped Reversing Valve
}

\author{
Yelin Li iD, Youxin Luo, and Xiao Wu \\ Hunan Province Cooperative Innovation Center for the Construction \& Development of Dongting Lake Ecological Economic \\ Zone, Hunan University of Arts and Science, Changde 415000, China
}

Correspondence should be addressed to Yelin Li; liyelin0403@aliyun.com

Received 26 February 2018; Revised 26 June 2018; Accepted 1 August 2018; Published 19 September 2018

Academic Editor: Miguel Neves

Copyright $(92018$ Yelin Li et al. This is an open access article distributed under the Creative Commons Attribution License, which permits unrestricted use, distribution, and reproduction in any medium, provided the original work is properly cited.

For the phenomenon of a hydraulic rock drill based on an underlapped reversing valve, the mechanical structure of the overlapped reversing form was proposed, which affected the pressure pulsation of the impact system, and motion of the impact piston was analyzed. The model of a hydraulic rock drill was built based on Newton's laws. The initial lead size of the reversing point was calculated by the equilibrium position of the damping piston and final velocity of the impact piston. The size of the overlapped reversing valve was designed and the best impact interval was calculated, according to pressure characteristic curves in the piston of the front-rear chamber and in the reversing valve of the left-right chamber, and the damping piston floating feature had an impact on initial lead size of the reversing point. The advantages of the overlapped reversing valve were analyzed, by contrasting the pressure pulsation of the impact system and motion of the impact piston with the underlapped reversing valve. The inner mechanism experiment of the hydraulic rock drill was designed to test the pressure characteristic curves in the piston of the frontrear chamber and in the reversing valve of the left-right chamber. The model of the overlapped reversing valve was verified by the experiment.

\section{Introduction}

Hydraulic rock drill is the development core of a modern hydraulic drill rig, which is widely used in mining, tunnel, and building industry, and its performance determined the working efficiency of the drill rig. In the face of large-scale mining and tunneling, improving the efficiency is the key to the development of the hydraulic rock drill. The impact piston and reversing valve are the core components in the research of inner mechanism, and the size of the overlapped valve is the most important condition to affect the pressure fluctuation characteristic during drilling [1-4].

The design method of the underlapped valve is mainly to avoid the phenomenon of the dead chamber and highpressure peak. This method can solve the problems like the peak of chamber's pressure is too high, but it is not suitable to improve the performance of the impact point and impact.
Shu et al. [5] proposed a mathematical model based on the theory of hydraulic oil volume compression; a joint analysis of the impact reversing system was carried out, but the opening of the reversing valve is not considered. The overlapped reversing valve is analyzed by $\mathrm{Hu}$ et al. [6], and the rationality of the overlapped reversing valve in the hydraulic rock drill is pointed out. The size of the negative opening is the key to influence the dynamic characteristics of the fluid, avoiding the mixture of high- and low-pressure oil and fluid, and at the same time, it improves the stability of the work of the shock device. However, the key problem affecting the efficiency of rock drills is not studied in this paper, but the interpretation of high-pressure and lowpressure oil mixing is made. Yang et al. [7] put forward the calculation content of the parameters of the reversing valve and discuss the relationship between the main structural parameters and the input parameters of the hydraulic impact mechanism. This analysis is based on the 
form of the overlapped reversing valve. The unified model of rock, buffer, impact, and reversing is established by $\mathrm{Oh}$ et al. [8]. The relationship between pressure of the pressure chamber and the law of piston motion and the relationship between rock hardness and rock drilling efficiency are analyzed. This article does not analyze the effect of the opening of the reversing valve on the impact piston rule.

The above analysis shows that the opening of the reversing valve is an important parameter affecting the internal motion law of the hydraulic rock drill. Take the rock drill with no continuous high pressure as an example, by exploring the relationship between the impact structure and the buffer structure, the underlapped, overlapped, and zero of the reversing valve as well as the influence of the opening structure of the reversing valve on the dynamic characteristics of the impact system are studied.

\section{Impact and Reversing Models}

Impact system is a key component of the hydraulic rock drill, which is mainly composed of cylinder, impact piston, reversing valve, high-pressure accumulator, and other structures. The impact piston connects the reversing valve with oil line in the cylinder. A high-pressure accumulator is connected by bolts on the left side of the damper cylinder, and its internal line is connected to the cylinder. An impact piston is axially reciprocated, and a reversing valve is radially reciprocated [9]. The impact and reverse system principle is shown in Figure 1.

The impact piston moves reciprocated under the action of oil in cylinder, according to the time of the reversing valve adjusting the reverse of the impact piston. The displacement and frequency of the impact piston can be adjusted through the position change of the stroke control bolt.

2.1. Impact Mechanism Model. Pressure and viscosity of oil, impact of oil compression, and seal friction force in the movement should be considered in mechanism modeling [10]. As shown in Figure 2, five keypoints are labeled, which describe the key information between return and stroke in the process of impact piston's movement.

The differential equation for the impact piston is

$$
m_{\mathrm{p}} \ddot{x}_{\mathrm{p}}+K_{\mathrm{p}} \dot{x}_{\mathrm{p}}+F_{1} \frac{\left|\dot{x}_{\mathrm{p}}\right|}{\dot{x}_{\mathrm{p}}}=A_{1} P_{1}+A_{2} P_{2}
$$

where $m_{\mathrm{p}}$ is the mass of the impact piston $(\mathrm{kg}), x_{\mathrm{p}}$ is the displacement of the impact piston ( $\mathrm{mm}), K_{\mathrm{p}}$ is the coefficient of viscous resistance, $F_{1}$ is the friction force of the seal $(\mathrm{N})$, $P_{1}$ is the pressure of the front chamber of the impact piston (MPa), $P_{2}$ is the pressure of the rear chamber of the impact piston (MPa), $A_{1}$ is the effective area of the impact piston in the front chamber $\left(\mathrm{mm}^{2}\right)$, and $A_{2}$ is the effective area of the impact piston in the rear chamber $\left(\mathrm{mm}^{2}\right)$.

The expression for $K_{\mathrm{p}}$ is

$$
K_{\mathrm{p}}=\frac{\pi \mu}{\sqrt{1-\varepsilon^{2}}}\left(\frac{d_{\mathrm{p} 1} L_{\mathrm{p} 1}}{h_{1}}+\frac{d_{\mathrm{p} 2} L_{\mathrm{p} 2}}{h_{2}}+\frac{d_{\mathrm{p} 2} L_{\mathrm{p} 3}}{h_{3}}+\frac{d_{\mathrm{p} 4} L_{\mathrm{p} 4}}{h_{4}}\right),
$$

where $\mu$ is the dynamic viscosity, $\mu=\nu \rho$, in which $\nu$ is the kinematic viscosity $\left(\mathrm{m}^{2} / \mathrm{s}\right)$ and $\rho$ is the density $\left(\mathrm{kg} / \mathrm{m}^{3}\right) ; \varepsilon$ is the eccentricity ratio, $\varepsilon=\sigma / h$, in which $\sigma$ is the eccentricity $(\mathrm{mm})$ and $h$ is the amount of clearance $(\mathrm{mm}) ; d_{\mathrm{p} i}$ is the diameter of the relative movement part among the impact piston, guide sleeve, and cylinder $(\mathrm{mm}) ; L_{\mathrm{p} i}$ is the length of the relative movement part among the impact piston, guide sleeve, and cylinder ( $\mathrm{mm})$; and $h_{i}$ is the fit clearance among the impact piston, guide sleeve, and cylinder $(i=1,2,3,4)$ (mm).

The friction force of seal devices $[11,12]$ is given by $F_{1}=\pi \cdot d_{\mathrm{p} 1} \cdot b \cdot f \cdot P_{1}+\pi \cdot d_{\mathrm{p} 4} \cdot b \cdot f \cdot P_{2}+2 \pi\left(d_{\mathrm{p} 1}+d_{\mathrm{p} 4}\right) \zeta$,

where $b$ is the seal width (mm), $f$ is the friction coefficient between the seal and piston $(f=0.05)$, and $\zeta$ is the compressibility correlation coefficient of O-ring $(\zeta=0.1)$.

The fluid continuity linear equation in the front chamber is given by

$$
\frac{A_{1}\left(l_{11}+l_{13}+x_{\mathrm{p}}\right)+A_{12} l_{12}}{K_{\text {lig }}} \cdot \frac{d P_{1}}{d t}=Q_{\mathrm{p} 1}-C_{3} Q_{\mathrm{u} 3}-A_{1} \dot{x}_{\mathrm{p}}-Q_{11} .
$$

The fluid continuity linear equation in the rear chamber is

$$
\frac{A_{2}\left(l_{14}+l_{16}-x_{\mathrm{p}}\right)+A_{15} l_{15}}{K_{\text {lig }}} \cdot \frac{d P_{2}}{d t}=A_{2} \dot{x}_{\mathrm{p}}-C_{4} \mathrm{Q}_{\mathrm{u} 5}-\mathrm{Q}_{\mathrm{l} 1}-\mathrm{Q}_{\mathrm{p} 2},
$$

where $l_{11}, l_{12}$, and $l_{13}$ are the length of each part of the front chamber (mm); $A_{12}$ is the cross-sectional area in the front chamber's groove $\left(\mathrm{mm}^{2}\right) ; Q_{\mathrm{pl}}$ is the inflow oil to the front chamber $(\mathrm{L} / \mathrm{min}) ; Q_{\mathrm{ul}}$ is the outflow oil from the front chamber; $C_{3}$ is the state judgement content, when highpressure oil connects with the front chamber, $C_{3}=1$, otherwise, $C_{3}=0 ; C_{4}$ is the state judgement content, when highpressure oil connects with the rear chamber, $C_{4}=1$, otherwise, $C_{4}=0 ; Q_{11}$ is the clearance leakage flow between the impact piston and cylinder $(\mathrm{L} / \mathrm{min}) ; K_{\text {lig }}$ is the oil elastic modulus $(\mathrm{MPa}), K_{\text {lig }}=1700 \mathrm{MPa} ; l_{14}, l_{15}$, and $l_{16}$ are the length of each part of the rear chamber (mm); $A_{15}$ is the cross-sectional area in the rear chamber's groove $\left(\mathrm{mm}^{2}\right) ; Q_{\mathrm{u} 4}$ is the outflow oil from pipeline $4(\mathrm{~L} / \mathrm{min})$; and $Q_{\mathrm{u} 5}$ is the outflow oil from pipeline $5(\mathrm{~L} / \mathrm{min})$.

2.2. Reversing Valve Mechanism Model. Reversing mechanism includes the reversing valve, cover, and limit structure, which makes various valve ports to be cooperated to change over the channel for the front-rear chamber.

The left valve chamber and the right valve chamber cooperate with the front chamber and the rear chamber of the impact piston. Keypoint 1 in Figure 2 is connected with keypoint 7 in Figure 3 when the pipeline is opened, $P_{3}=P_{2}$. Keypoint 5 in Figure 2 is connected to keypoint 1 in Figure 3 when the pipeline is opened, $P_{4}=P_{1}$. 


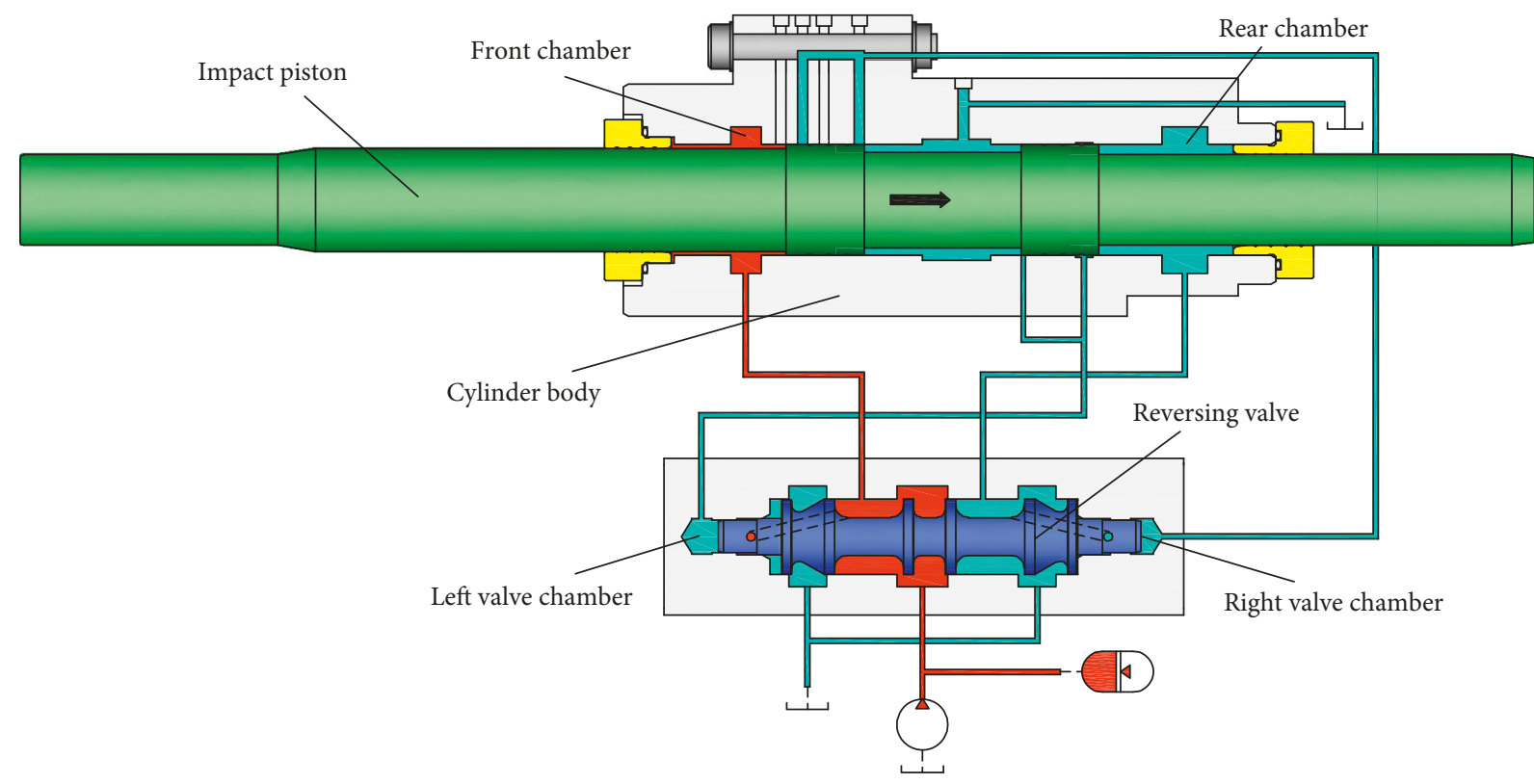

FIGURE 1: Impact and reversing mechanism principle.

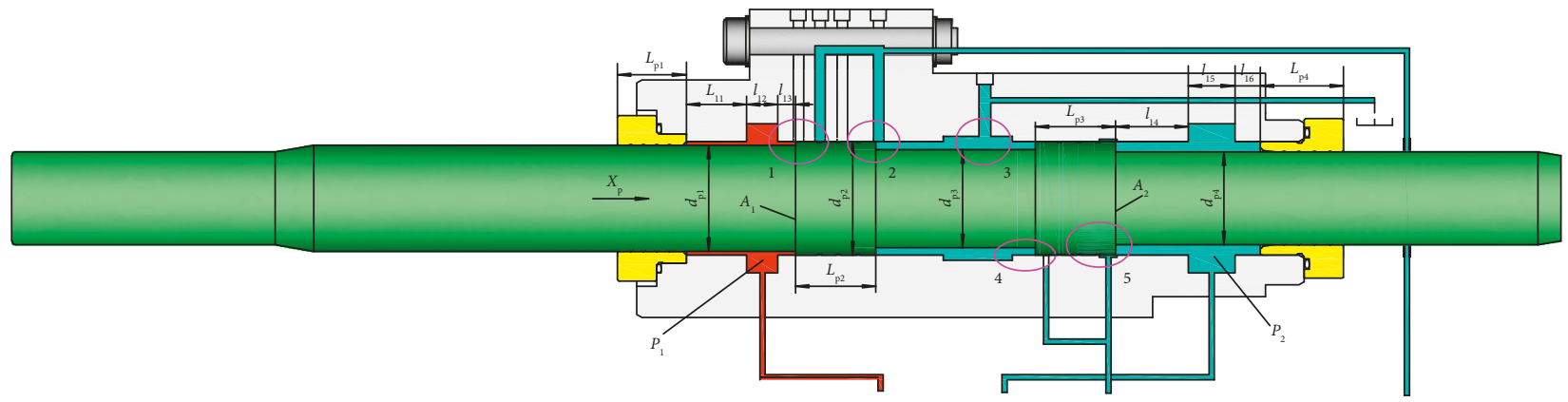

Figure 2: Impact mechanism.

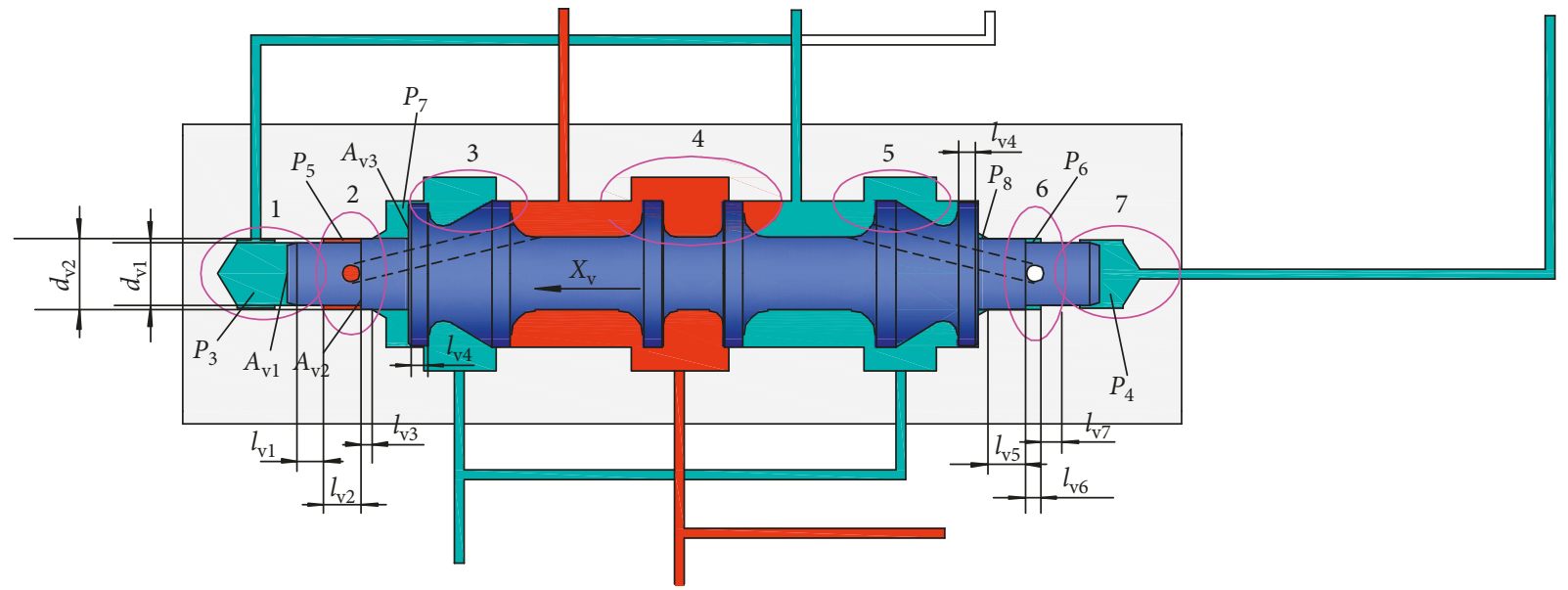

FIgURE 3: Reversing mechanism principle.

In Figure 3, keypoint 1 is the left valve chamber and keypoint 7 is the right valve chamber, where the pressure acts on when reversing valve changing-over; keypoints 2 and 6 are the chambers which can push the valve to limit position in initial status; keypoints 3 and 5 are valve ports of oil return pipe, meanwhile, which are damping zones of the reversing valve; and keypoint 4 is the input pipe $[13,14]$. 
The differential equation for movement of the reversing valve is given by

$$
\begin{aligned}
m_{\mathrm{v}} \ddot{x}_{\mathrm{v}}+K_{\mathrm{v}} \dot{x}_{\mathrm{v}}= & A_{\mathrm{v} 1} P_{4}+A_{\mathrm{v} 2} P_{6}+A_{\mathrm{v} 3} P_{8} \\
& -A_{\mathrm{v} 1} P_{3}-A_{\mathrm{v} 2} P_{5}-A_{\mathrm{v} 3} P_{7},
\end{aligned}
$$

where $m_{\mathrm{v}}$ is the mass of the reversing valve $(\mathrm{kg}) ; x_{\mathrm{v}}$ is the displacement of the reversing valve $(\mathrm{mm}) ; K_{\mathrm{v}}$ is the coefficient of viscous resistance; $P_{3}$ is the pressure of the left valve chamber $(\mathrm{MPa}) ; P_{4}$ is the pressure of the right valve chamber $(\mathrm{MPa}) ; P_{5}$ is the initial return pressure on the left side $(\mathrm{MPa}) ; P_{6}$ is the initial return pressure on the right side $(\mathrm{MPa}) ; P_{7}$ is the damping pressure on the left side $(\mathrm{MPa}) ; P_{8}$ is the damping pressure on the right side $(\mathrm{MPa})$; and $A_{\mathrm{vl}}$, $A_{\mathrm{v} 2}$, and $A_{\mathrm{v} 3}$ are the compression area of the reversing valve $\left(\mathrm{m}^{2}\right)$.

The expression for $K_{\mathrm{v}}$ is

$$
\begin{aligned}
K_{\mathrm{v}}= & \frac{\pi \mu}{\sqrt{1-\varepsilon^{2}}}\left[\frac{d_{\mathrm{v} 1} C_{4}\left(l_{\mathrm{v} 1}-x_{\mathrm{v}}\right)+C_{4}\left(x_{\mathrm{v}}-l_{\mathrm{v} 2}\right)}{h_{\mathrm{v} 1}}\right. \\
& \left.+\frac{d_{\mathrm{v} 2}\left(l_{\mathrm{v} 2}-x_{\mathrm{v}}\right)}{h_{\mathrm{v} 2}}+\frac{d_{\mathrm{v} 3}\left(l_{\mathrm{v} 3}-x_{\mathrm{v}}\right)}{h_{\mathrm{v} 3}}\right],
\end{aligned}
$$

where $l_{\mathrm{v} 1}, l_{\mathrm{v} 2}$, and $l_{\mathrm{v} 3}$ are the length of each part between the reversing valve and cylinder $(\mathrm{mm})$ and $h_{\mathrm{v} 1}, h_{\mathrm{v} 2}$, and $h_{\mathrm{v} 3}$ are the amount of clearance between the reversing valve and cylinder ( $\mathrm{mm})$.

The fluid continuity linear equation for the left valve chamber is

$$
\frac{A_{\mathrm{vl}} l_{\mathrm{v}}}{K_{\text {lig }}} \cdot \frac{d P_{3}}{d t}=A_{15} \dot{x}_{\mathrm{v}}-Q_{15}-Q_{\mathrm{vl}},
$$

where $Q_{15}$ is the leakage flow from the high-pressure chamber to the left valve chamber $(\mathrm{L} / \mathrm{min})$ and $Q_{\mathrm{v} 1}$ is the leakage flow from the left valve chamber to the return pipe (L/min).

The fluid continuity linear equation for the right valve chamber is

$$
\frac{A_{\mathrm{v} 1} l_{\mathrm{v} 0}}{K_{\text {lig }}} \cdot \frac{d P_{4}}{d t}=A_{\mathrm{v} 1} \dot{x}_{\mathrm{v}}-Q_{16}-Q_{\mathrm{v} 2},
$$

where $Q_{16}$ is the leakage flow from the right chamber to the pipe (L/min) and $Q_{v 2}$ is the flow from the high-pressure chamber to the right chamber $(\mathrm{L} / \mathrm{min})$.

\section{Optimum Impact Interval}

3.1. Initial Lead Size of the Reversing Point. The moment $t_{\mathrm{h} 0}$ is when the valve starts to reverse, at the time of $t_{\mathrm{h} 0}$. The matching position relation among the damping piston, impact piston, and reversing valve is shown in Figure 4. The point "a" is a static equilibrium position of the damping piston, point " $b$ " is the critical position where the signal hole is going to open and connect the left valve chamber with high-pressure oil, and point " $c$ " is the reversing valve displacement. The initial lead size of the reversing point $L_{\mathrm{t}}$ means the distance between the impact piston and shank under the condition of the static equilibrium position of the damping piston at the time of $t_{\mathrm{h} 0}[15,16]$.

Before the simulation, some parameters are set based on the balance of flow, the compression characteristics of hydraulic oil, and the coordination of the motion of the impact system, and the setting of the initial parameters of the impact system is shown in Table 1.

The equations are solved by using the ODE45 method in the MATLAB tool. The simulation curves of velocity and displacement of the impact piston and reversing valve are shown in Figure 5.

As shown in Figure 5, from the moment $t_{\mathrm{h} 0}$ of the reversing point to the moment $t_{\mathrm{h} 1}$ of the impact point, the impact piston displacement is $11.7 \mathrm{~mm}$, As a result of analysis, the optimum impact point is the moment which links the front chamber with high-pressure oil. Based on the displacement of the piston, set the initial lead size of the reversing point $L_{t}$ as $11.7 \mathrm{~mm}$; if $L_{t}<11.7 \mathrm{~mm}$, the impact piston would impact the shank with the velocity which is not maximum; if $L_{t}>11.7 \mathrm{~mm}$, the impact piston would impact the high-pressure oil to make the velocity decline before hitting the shank because the reversing valve has reversed.

To summarize, the underlapped reversing valve is easy to cause high-pressure oil and low-pressure oil to get mix up and make the impact piston impact the high-pressure oil to make the velocity decline before hitting the shank. If we choose the overlapped reversing valve, it will help us keep high pressure in the rear chamber when the piston impacts the shank and get maximum velocity for the impact piston.

3.2. Overlapped Quantity. When a hydraulic rock drill drills rocks, because of the stress wave reflected and absorption of the damping system, the static equilibrium position of the damping piston changes tinily, which would lead to the initial lead size of the reversing point to change; then, it can not be sure that impact occurs at the top velocity point. The flow area of the damping piston oil drain path has been discussed [17], and the balance position of the damping piston is determined to be between 0 and $1.8 \mathrm{~mm}$, which means the change interval of initial lead size of the reversing point is $0 \sim 1.8 \mathrm{~mm}$. The design of the overlapped reversing valve's size can make impact piston not be declined when initial lead size of the reversing point changed.

According to the above analysis, it reveals the importance of comparing the velocity and displacement curve of the impact piston and the displacement curve of the reversing valve. The top velocity of the impact piston is $v_{\text {impact }}=12 \mathrm{~m} / \mathrm{s}$, the maximum stroke of initial lead size of the reversing point $L_{t}$ is $x_{\mathrm{pt}}=1.8 \mathrm{~mm}$, and the time $\Delta t_{\mathrm{h}}$ can be calculated by

$$
\begin{aligned}
& x_{\mathrm{pt}}=v_{\text {impact } 0} t_{\mathrm{h} 1}+\frac{1}{2} a_{\text {impactp }} \Delta t_{\mathrm{h}}^{2}, \\
& \Delta t_{\mathrm{h}}=\sqrt{\frac{2\left(x_{\mathrm{pt}}-v_{\text {impact } 0} t_{\mathrm{h} 1}\right)}{a_{\text {impactp }}}},
\end{aligned}
$$




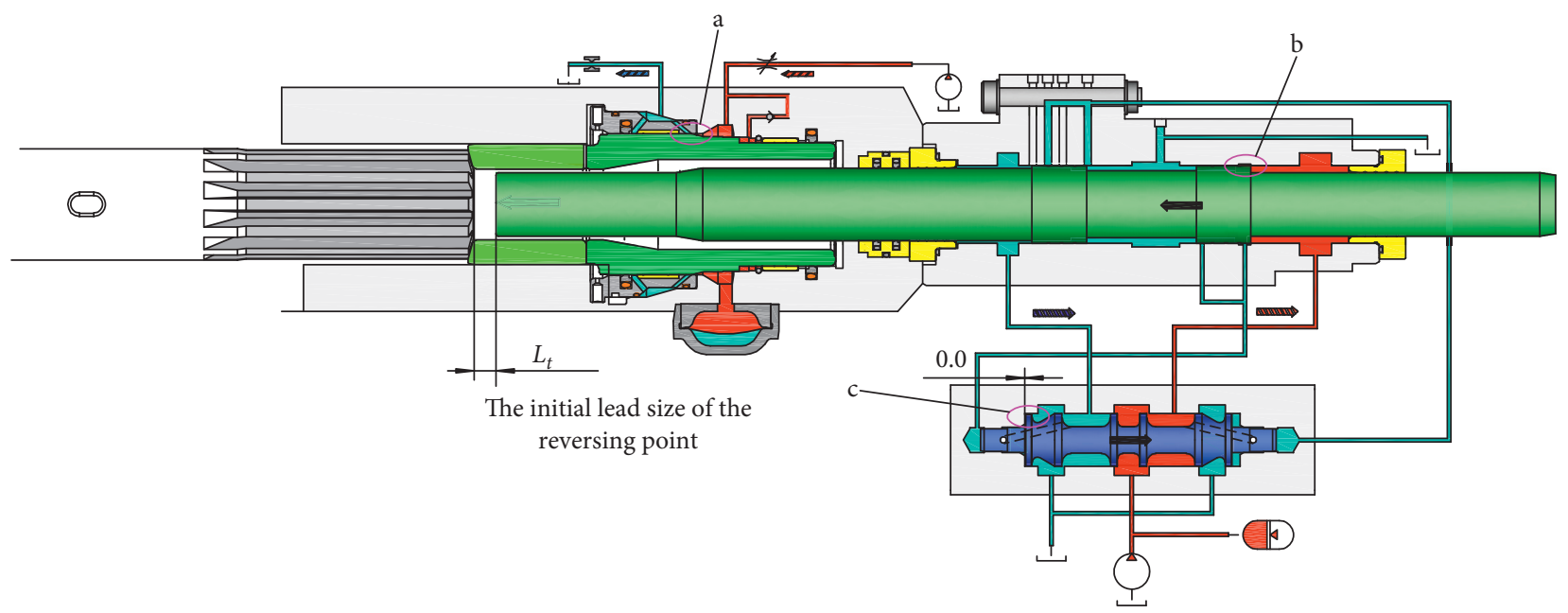

FIgURE 4: The position of the impact and damping piston when the reversing valve starts to reverse.

TABLE 1: The parameter selection of the impact system.

\begin{tabular}{lcc}
\hline Initial parameters & $\begin{array}{c}\text { Numerical } \\
\text { value }\end{array}$ & Unit \\
\hline The impact of inlet oil pressure & 20 & $\mathrm{MPa}$ \\
Return oil pressure & 2 & $\mathrm{MPa}$ \\
Impact piston mass & 5 & $\mathrm{~kg}$ \\
Reversing valve mass & 0.38 & $\mathrm{~kg}$ \\
Boss diameter of the front chamber piston & 44 & $\mathrm{~mm}$ \\
Diameter of the front piston rod & 41 & $\mathrm{~mm}$ \\
Boss diameter of the rear chamber piston & 44 & $\mathrm{~mm}$ \\
Diameter of the rear piston rod & 36 & $\mathrm{~mm}$ \\
Acceleration stroke of piston return & 26.5 & $\mathrm{~mm}$ \\
Left effect diameter of the revising valve & 13 & $\mathrm{~mm}$ \\
Right effect diameter of the revising valve & 13 & $\mathrm{~mm}$ \\
Revising valve stroke & 4 & $\mathrm{~mm}$ \\
Accumulator inflating volume & 0.12 & $\mathrm{~L}$ \\
Accumulator inflating pressure & 10 & $\mathrm{MPa}$ \\
\hline
\end{tabular}

where $t_{\mathrm{h} 1}$ is the moment with which the impact piston impacts the shank with minimum stroke of initial lead size of the reversing point $L_{\mathrm{t}}(\mathrm{ms}), x_{\mathrm{pt}}$ is the maximum stroke of initial lead size of the reversing point $(\mathrm{mm}), v_{\text {impact0 }}$ is the velocity with which the impact piston impacts the shank with minimum stroke of initial lead size of the reversing point $L_{\mathrm{t}}(\mathrm{m} / \mathrm{s})$, and $a_{\text {impactp }}$ is the acceleration of the impact piston $\left(\mathrm{m} / \mathrm{s}^{2}\right)$, defined as follows:

$$
a_{\text {impactp }}=\frac{A_{2} P_{2}-A_{1} P_{1}}{m_{\mathrm{p}}} .
$$

$\Delta t_{3}$ is the time it takes to propagate pressure from the high-pressure oil to the valve chamber at the moment of pressure changes because a signal hole in the cylinder's rear chamber is being opened:

$$
\Delta t_{3}=\frac{l}{c}
$$

where $l$ is the length of pipe between the rear chamber and valve chamber $(\mathrm{mm})$ and $c$ is the velocity of pressure wave propagation $(\mathrm{m} / \mathrm{s})(c=4000 \mathrm{~m} / \mathrm{s})$.

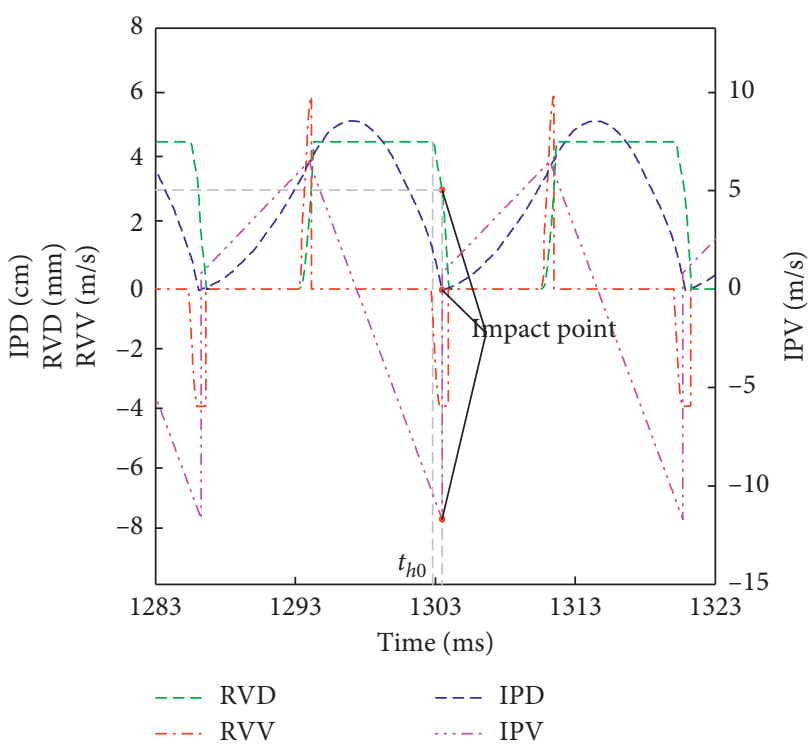

FIGURE 5: The simulation curves of displacement and velocity of the reversing valve and impact piston. IPD: impact piston displacement; IPV: impact piston velocity; RVD: reversing valve displacement; RVV: reversing valve velocity.

Put $\Delta t_{\mathrm{h}}$ and $\Delta t_{3}$ in formula (10), and then the displacement of the valve is overlapped quantity $S_{\mathrm{v} 1}$ :

$$
s_{\mathrm{v} 1}=v_{\mathrm{hv} 1} t_{\mathrm{h} 1}+\frac{1}{2} a_{\mathrm{hv}}\left(\Delta t_{\mathrm{h}}-\Delta t_{3}\right)^{2},
$$

where $v_{\mathrm{hvl}}$ is the velocity of the reversing valve at $t_{\mathrm{h} 0}$ moment with minimum stroke initial lead size of the reversing point $L_{\mathrm{t}}(\mathrm{m} / \mathrm{s})$ and $a_{\mathrm{hv}}$ is the acceleration of the reversing valve in the reversing process $\left(\mathrm{m} / \mathrm{s}^{2}\right)$, defined as follows:

$$
a_{\mathrm{hv}}=\frac{P_{\mathrm{hv}}\left(A_{\mathrm{v}}-A_{\mathrm{v} 1}\right)}{m_{\mathrm{v}}},
$$

where $P_{\mathrm{hv}}$ is the pressure of the reversing valve's chamber in the impact interval $(\mathrm{MPa}), m_{\mathrm{v}}$ is the reversing valve mass (kg), $A_{\mathrm{v}}$ is the compression area of the reversing valve's 
chamber $\left(\mathrm{mm}^{2}\right)$, and $A_{\mathrm{v} 1}$ is the compression area of the inner side to auxiliary locate reversing valve $\left(\mathrm{mm}^{2}\right)$.

Through calculating, the optimum opening quantity $S_{\mathrm{v} 1}=0.57 \mathrm{~mm}$, in order to machine convenient, take the size of overlapped $S_{\mathrm{v} 1}$ to be $0.6 \mathrm{~mm}$. According to the above analysis, the change of initial lead size of the reversing point $L_{t}$ can be solved by taking the quantity of overlapped $S_{\mathrm{v} 1}=0.6 \mathrm{~mm}$.

\section{Comparative Analysis of the Reversing Valve}

To discuss the influence of the hydraulic rock drill made by the opening of the reversing valve, take the curve of underlapped, zero, and overlapped valves' opening quantity to simulation, and the data of the reversing valve are shown in Table 2.

According to the established parameters, the simulation result of the pressure of the front-rear chamber, the velocity and displacement curve of the impact piston is shown in Figure 6.

As shown in area "a" in Figure 6, negative pressure exists in the overlapped reversing valve after pressure drops and does not exist in the underlapped reversing valve or zero reversing valve. The negative pressure contributes to the cavitation phenomenon and breaks the guide sleeve or other parts, and the damaged residue can abrase the impact piston, cylinder, and other important parts.

As shown in enlarged figure of areas " $b$ and $c$," the overlapped reversing valve contributes to appearance of a higher peak when the pressure changes in the front chamber and rear chamber, the peak valve of pressure can get to $30 \sim 37 \mathrm{MPa}$, and the peak is relatively stable when pressure transitions between the front chamber and rear chamber with underlapped and overlapped valves.

As shown in enlarged figure of the area "c," the high pressure in the rear chamber of the overlapped reversing valve is kept preferably, the impact peak of rear chamber pressure is near the pressure switching point, and the impact point is in ideal position. Both underlapped reversing valve and zero reversing valve have a weak ability to keep high pressure in the rear chamber, and the pressure decreases significantly; the impact peak of the rear chamber appears lately, and the position of the impact point is delayed.

The energy of the impact piston is the storage of the return trip and the release of the stroke trip. The position of the maximum energy should be the impact point. The energy of the underlapped opening form of the reversing valve has been lost during the deceleration movement because the impact piston is on the stroke and the pressure of the rear chamber is smaller than that of the front chamber, so the velocity of piston has decreased, as shown in Figure 7.

As shown in enlarged figure of area "d" in Figure 7, the impact piston return trip velocity of underlapped, overlapped, and zero valves is basically consistent, and the time of underlapped and zero openings is advanced a little.

As shown in enlarged figure of area "e," the impact point of the impact piston coincides with the maximum velocity point of the impact piston's stroke under the overlapped reversing valve; however, when the reversing valve is underlapped or zero, the impact point of the impact piston is not the maximum velocity point, which shows that the initial lead size of the reversing point is too much larger.
TABLE 2: Reversing valve data.

\begin{tabular}{lcc}
\hline Number & Opening form & $\begin{array}{c}\text { Opening } \\
\text { quantity }(\mathrm{mm})\end{array}$ \\
\hline 1 & Underlapped & 0.6 \\
2 & Zero & 0 \\
3 & Overlapped & -0.6 \\
\hline
\end{tabular}

As shown in area " $b$ " in Figure 6 and area "e" in Figure 7, because the overlapped reversing valve has a strong ability to keep high pressure in the rear chamber, the end velocity of impact is bigger; meanwhile, both underlapped and zero reversing valves have a weak ability to keep high pressure in the rear chamber, so they contribute less to the final velocity of the impact.

\section{Experimental Verification}

In order to verify the correctness of the model, the authors performed several experiments on the characteristics of pressure curves of the hydraulic rock drill during normal operation. The rock drill is installed on the test platform, which impacts the accepting-impact cylinder through a drill rod. The pressure of the accepting-impact cylinder can be adjusted to simulate the rock with different hardness, and the principle of the experimental system is shown in Figure 8 . Figure 9 presents one picture of the experiment setup.

The pressure sensor needs $10 \mathrm{~V}$ DC power supply, the maximum power supply voltage of the signal amplifier can reach $10 \mathrm{~V}$, the pressure sensor outputs the signal through the signal amplifier, and the output signal unit is $\mathrm{mV}$. So the output signal needs to adjust to the maximum value of $10 \mathrm{~V}$ by amplifier, and the calibration test is carried out; zero setting before testing is shown in Table 3.

Propulsion pressure, inflow pressure, damping pressure, and other experimental parameters are set in Table 4.

5.1. Comparison of Pressure Curves of Front and Rear Chambers of the Impact Piston. The output data of the experiment are shown in Figure 10. It indicates the pressure of front and rear chambers switched alternately, and the instant of switching was almost perpendicular, impact piston with the action of high pressure in the front and rear chamber at 19.5 MPa. Meanwhile, in the process of pressure switching, the peak value should not be higher (the seal, O-ring have capability of adapting high pressure under $200 \mathrm{MPa}$ ); the pressure of the rear chamber did not drop rapidly during the piston stroke process (kept the piston stroke at a high velocity), comparing the simulation and test waveforms and discussing the correctness of the simulation model.

As it can be learned from Figure 10, the peak time and the change law of front-rear chamber's pressures of simulation curves are very consistent with the experimental curve. The impact point position is correct, and the pressure peak value is similar in the moment of front and rear chamber changes. It can be seen that the impact system model can express the characteristics of pressure of front and rear chambers of impact mechanism. 

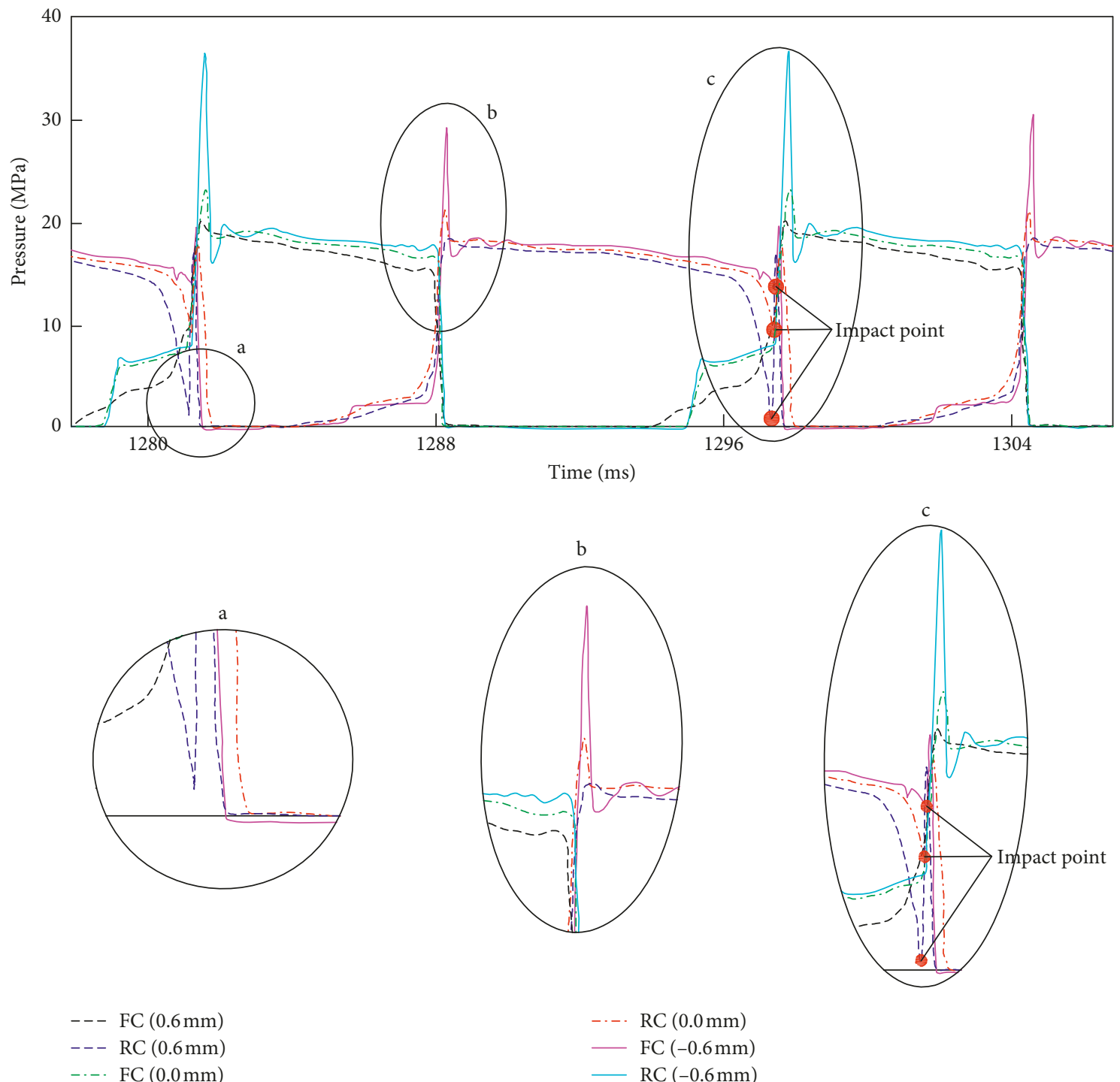

FIGURE 6: Comparison of front chamber (FC) and rear chamber (RC) pressures among underlapped, zero, and overlapped reversing valves. Note. a: the amplification of negative pressure; b: the amplification of the peak; c: the amplification of the impact point.

Because of the interference of external signals and the vibration of oil in pipelines, the fluctuation of experimental data is more obvious, the simulation data are relatively mild, but the general law is consistent.

\subsection{The Pressure Curves Comparison of Reversing Valve's Left} and Right Chambers. The reversing valve is the key part in shift stroke of the impact piston; the velocity of the reversing valve cannot be too fast or too slow, which needs to be switched correctly in the movement process of the impact piston, and the curves of the experiment and simulation pressure are shown in Figure 11.

As it can be seen from Figure 11, the pressure duration time is about $2 \mathrm{~ms}$ between the simulation curve and the experimental curve of left and right valve chambers, the pressure value of the left valve chamber is about $10 \mathrm{MPa}$, the pressure value of the right valve chamber is about $19.5 \mathrm{MPa}$, and the curve of the reversing valve can well describe the pressure characteristics of the reversing mechanism of the hydraulic rock drill. For the same reason of curves in front and rear chambers, the fluctuation of experimental data is more obvious, the simulation data are relatively mild, but the general law is consistent.

\section{Conclusion}

The impact and reversing mechanism model of a hydraulic rock drill is set up. The concept of initial lead size of the reversing point is put forward, the design quantity of the overlapped valve is calculated, according to the characteristics of the overlapped valve, the optimum impact range of the impact system is obtained, and the advantages of the overlapped reversing valve are analyzed.

The influences of underlapped, overlapped, and zero reversing valves on the pressure of front and rear chambers of the impact system and the velocity of impact of the impact piston are analyzed in this paper. 

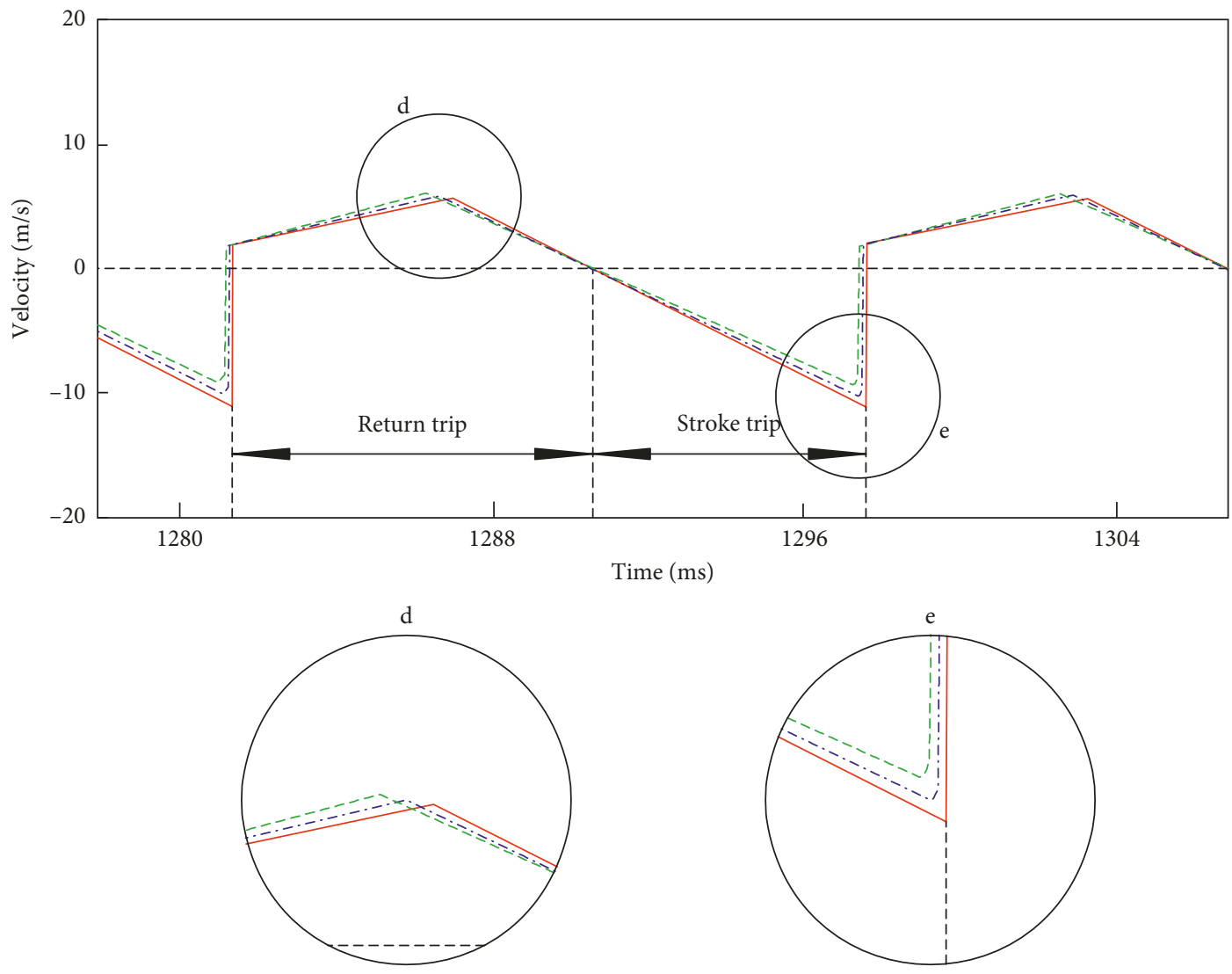

$$
\begin{array}{ll}
--- & 0.6 \mathrm{~mm} \\
-.- & 0.0 \mathrm{~mm} \\
- & -0.6 \mathrm{~mm}
\end{array}
$$

Figure 7: Velocity curves of the impact piston among underlapped, zero, and overlapped reversing valves. Note. d: the amplification of return trip; e: the amplification of stroke trip.

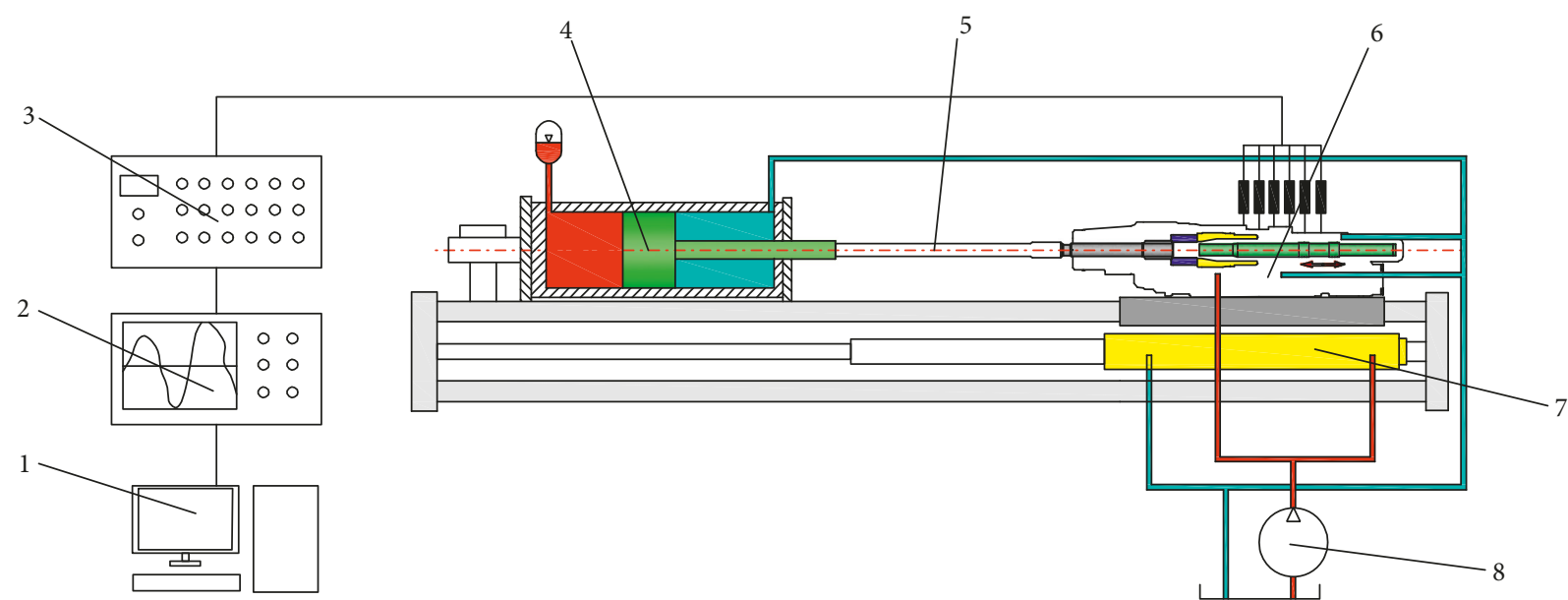

FIGURE 8: Impact and reversing mechanism principle. 1: computer; 2: data acquisition system; 3: signal amplifier; 4: accepting-impact cylinder; 5: drill rod; 6: hydraulic rock drill; 7: propulsion cylinder; 8: hydraulic pumping station.

The pressure peak of the underlapped reversing valve in the process of pressure conversion between the front chamber and rear chamber is small, and the change is relatively stable; however, the durability of the rear chamber to keep high pressure is poor in the stroke phase, which leads to the fast deceleration of velocity of the impact piston, and the impact point lagged.

Although the pressure peak of the negative opening valve is larger in the process of pressure conversion in the front and rear chambers, the compressive strength of the sealing 


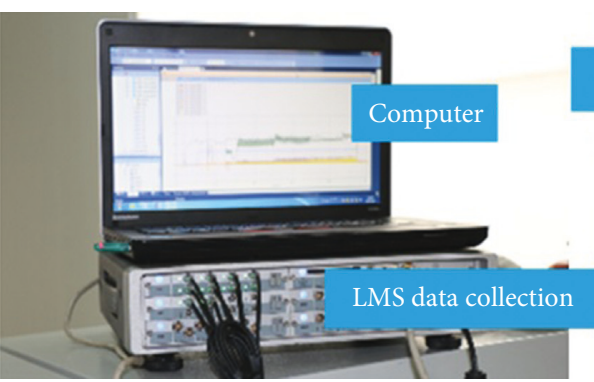

(a)

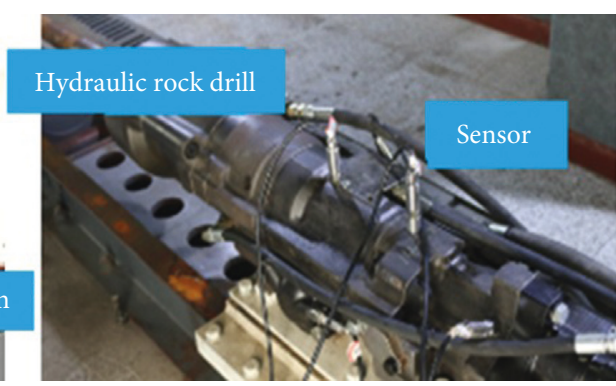

(b)

FIGURE 9: Picture of the experiment: (a) the connection between the computer and LMS data collection; (b) the connection between the hydraulic rock drill and sensors.

TABLE 3: Signal amplifier zero setting.

\begin{tabular}{lccc}
\hline Number & Test item & Zero adjustment & Acquisition channel \\
\hline 1 & Front chamber & 0.001 & C2 \\
2 & Rear chamber & -0.005 & $\mathrm{C} 3$ \\
3 & Left valve chamber & -0.008 & $\mathrm{C} 4$ \\
4 & Right valve chamber & -0.002 & $\mathrm{C} 1$ \\
\hline
\end{tabular}

TABLE 4: Test initial data setting.

\begin{tabular}{lccc}
\hline Number & Parameter name & Setting valve (MPa) & Display mode \\
\hline 1 & Inflow pressure of impact & 20 & Sensor \\
2 & No-load damping pressure & 3.5 & Sensor \\
3 & Propulsion pressure & 3.7 & Sensor \\
4 & Initial nitrogen-charging pressure of a damping & 3.5 & Gauge pressure \\
5 & accumulator & 11.5 & Gauge pressure \\
\hline
\end{tabular}

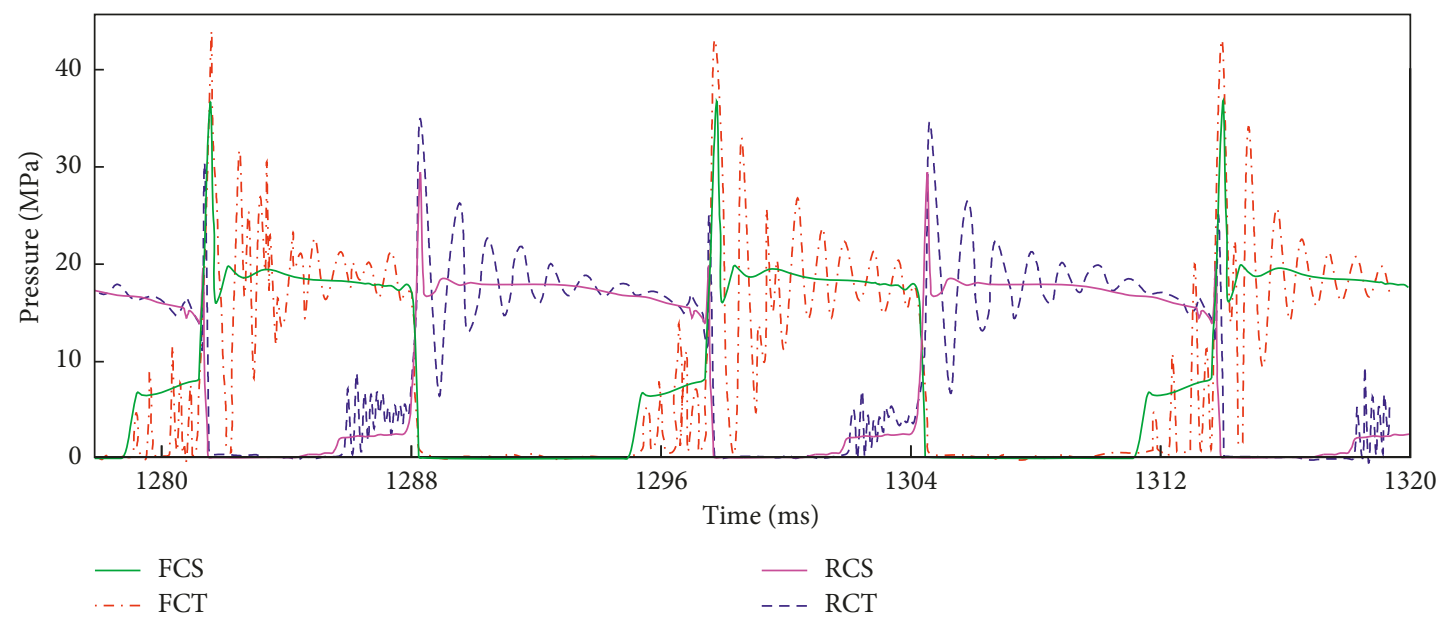

FIGURE 10: Comparison between simulation and test curves in front and rear chambers. FCS: front chamber simulation curve; FCT: front chamber testing curve; RCS: rear chamber simulation curve; RCT: rear chamber testing curve. 


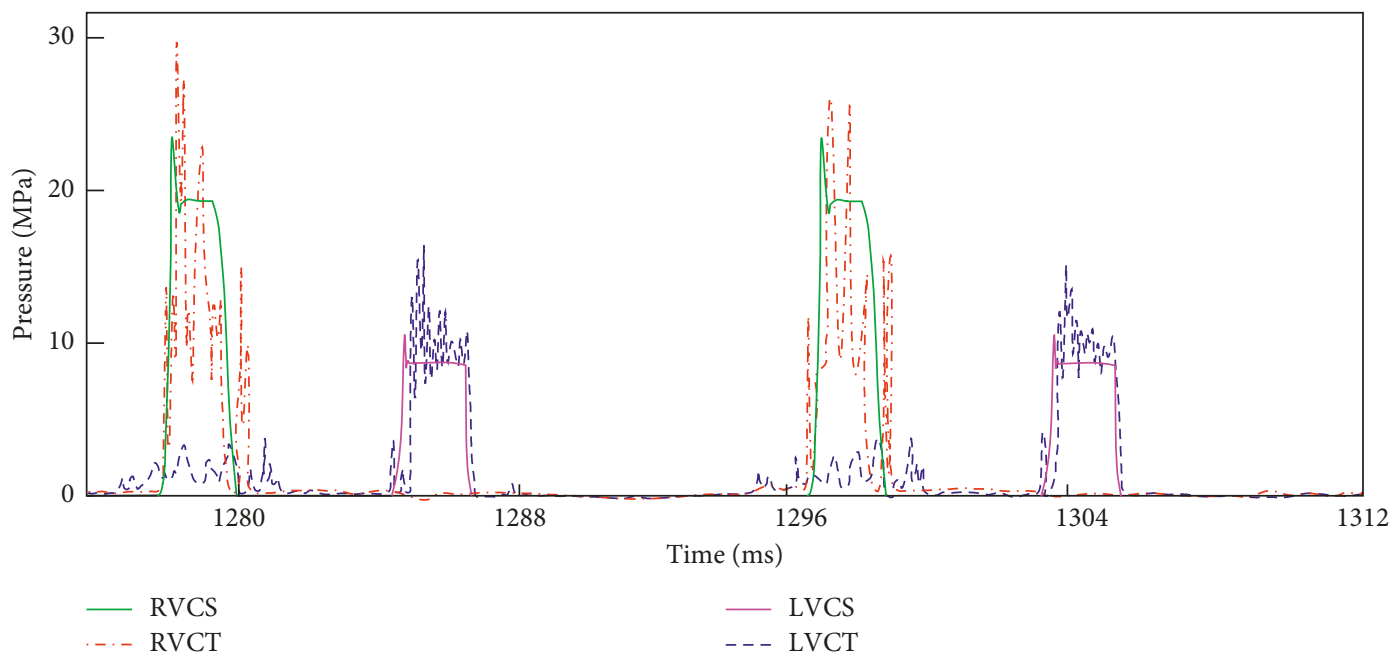

FIGURE 11: Comparison between simulation and test curves in left and right valve chambers. RVCS: right valve chamber simulation curve; RVCT: right valve chamber testing curve; LVCS: left valve chamber simulation curve; LVCT: left valve chamber testing curve.

ring and the seal is up to $200 \mathrm{MPa}$, which solves the peak value caused by the high pressure of the overlapped valve, but the cavitation phenomenon caused by the negative pressure problem has not been solved well. The main advantage of the overlapped reversing valve is to increase the best impact interval of the impact piston so that the impact piston can impact the drill rod with the highest speed.

The experimental method is designed to obtain the change law of the internal pressure of the hydraulic rock drill. The simulation results are compared with the experimental results. Through the experimental data, the trend of the pressure curve is similar to that of the model. The correctness of the model of the overlapped opening reversing valve is verified. The model is used to simulate the structure of overlapped, zero, and underlapped reversing valves, and the applied theoretical data of the dynamic characteristics of the overlapped reversing valve are obtained.

\section{Data Availability}

The data used to support the findings of this study are available from the corresponding author upon request.

\section{Conflicts of Interest}

The authors declare that they have no conflicts of interest.

\section{Acknowledgments}

This research was sponsored by the Education Department General Item of Hunan Province (Grant no. 16C1090), Dr. Research Foundation from Hunan University of Arts and Science (Grant no. 16BSQD20), General project of Changde science and Technology Bureau CCQZ[2018]6, "R\&D and Industrialization of Rock Drilling Machines" (Grant no. XJT
[2014]239), Industrialization Development Project of Technological Achievements of Universities in Hunan Province (15CY008), and The Construct Program of the Key Discipline in Hunan Province (Mechanical Design and Theory) (XJF2011[76]), Cooperative Demonstration Base of Universities in Hunan.

\section{References}

[1] Q. Hu, C. Yang, H. Zheng, and M. Chen, "Dynamic simulation and test research of impact performance of hydraulic rock drill with no constant-pressurized chamber," Automation in Construction, vol. 37, pp. 211-216, 2014.

[2] A. Arffman, M. Marjamaki, and J. Keskinen, "Simulation of low pressure impactor collection efficiency curves," Journal of Aerosol Science, vol. 42, no. 5, pp. 329-340, 2011.

[3] B. J. Ryu, H. H. Han, G. S. Lee, K. Y. Ahn, and C. R. Lee, "Dynamic response analysis of a cantilevered beam due to an elastic impact," International Journal Precision Engineering and Manufacturing, vol. 11, no. 4, pp. 539-547, 2010.

[4] W. Y. Tian, M. Hu, C. X. Zhu et al., "Design on part of structural parameters of hydraulic rock drill," Journal of Northeastern University, vol. 27, no. 10, pp. 1134-1137, 2006.

[5] M. F. Shu, Q. H. He, H. Q. Zhao et al., "Study on simulation of impact performance and working pressure of hydraulic drifter," Journal of Wuhan University of Technology, vol. 33, no. 8, pp. 133-137, 2011.

[6] J. P. Hu and Q. Hu, "Oil pressure pulse features of a hydraulic impactor with an overlapped oil distributing valve," Journal of Vibration and Shock, vol. 33, no. 24, pp. 158-163, 2014.

[7] G. P. Yang, R. L. Wang, B. Chen, and J. H. Gao, "Modeling and simulation of hydraulic breaker system," China Journal of High way and Transport, vol. 24, no. 3, pp. 121-126, 2011.

[8] J. Y. Oh, G. H. Lee, H. S. Kang, and C. S. Song, "Modeling and performance analysis of rock drill drifters for rock stiffness," International Journal Precision Engineering and Manufacturing, vol. 13, no. 12, pp. 2187-2193, 2012.

[9] M. H. Chiang, C. C. Chen, and C. F. J. Kuo, "The high response and high efficiency velocity control of a hydraulic injection molding machine using a variable rotational speed 
electro-hydraulic pump-controlled system," International Journal of Advanced Manufacturing Technology, vol. 43, no. 910, pp. 841-851, 2009.

[10] D. Lovrec, M. Kastrevc, and S. Ulaga, "Electro-hydraulic load sensing with a speed-controlled hydraulic supply system on forming-machines," International Journal of Advanced Manufacturing Technology, vol. 41, no. 11-12, pp. 1066-1075, 2009.

[11] G. L. Cavanough, M. Kochanek, J. B. Cunningham, and L. D. Gipps, "A self-optimizing control system for hard rock percussive drilling," IEEE/ASME Transactions on Mechatronics, vol. 13, no. 2, pp. 153-157, 2008.

[12] K. Y. Kim, C. Y. Kim, and K. S. Kim, "Assessment of hydraulic drilling data on homogeneous rock mass," Journal of Korean Society for Rock Mechanics, vol. 18, no. 6, pp. 480-490, 2008.

[13] X. J. Lu and M. H. Huang, "Novel multi-level modeling method for complex forging processes on hydraulic press machines," International Journal of Advanced Manufacturing Technology, vol. 79, no. 9-12, pp. 1869-1880, 2015.

[14] B. Lundberg and M. Okrouhlik, "Influence of 3D effects on the efficiency of percussive rock drilling," International Journal of Impact Engineering, vol. 25, no. 4, pp. 345-360, 2001.

[15] Y. L. Li, F. Ma, and X. G. Geng, "Dynamic characteristics on double damping system of heavy hydraulic rock drill," Journal of China Coal Society, vol. 40, no. 7, pp. 1684-1691, 2015.

[16] Y. L. Li, F. Ma, and X. G. Geng, "Optimal design of performance parameters for the double damping system of a hydraulic rock drill," Chinese Journal of Engineering, vol. 37, no. 9, pp. 1183-1190, 2015.

[17] Y. L. Li, F. Ma, and X. G. Geng, "Effect of annular clearance inside the double damping chamber on the dynamic characteristics of a rock drill damping system," Journal of University of Science and Technology Beijing, vol. 36, no. 12, pp. 1676-1682, 2014. 


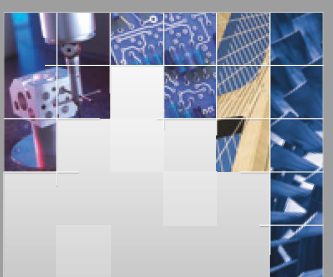

\section{Enfincering}
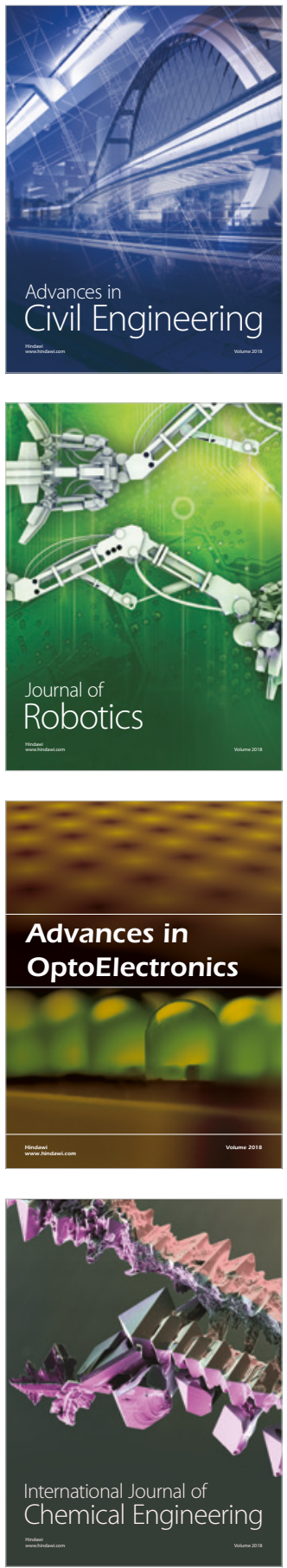

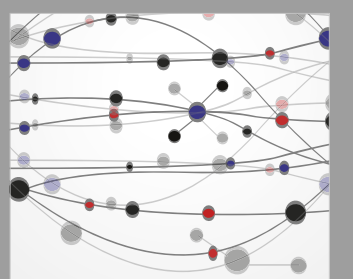

\section{Rotating \\ Machinery}

The Scientific World Journal

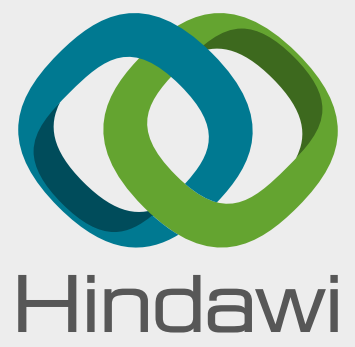

Submit your manuscripts at

www.hindawi.com
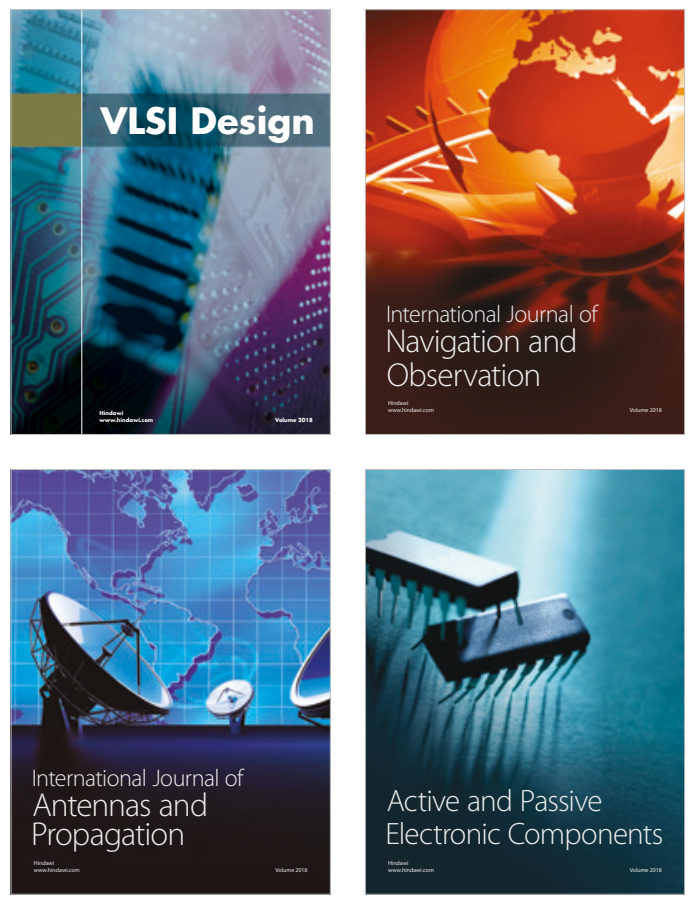
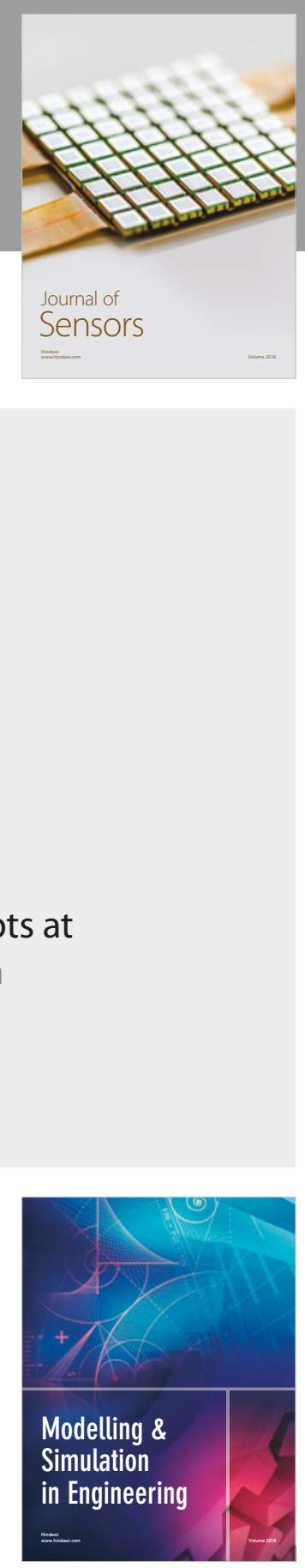

\section{Advances \\ Multimedia}
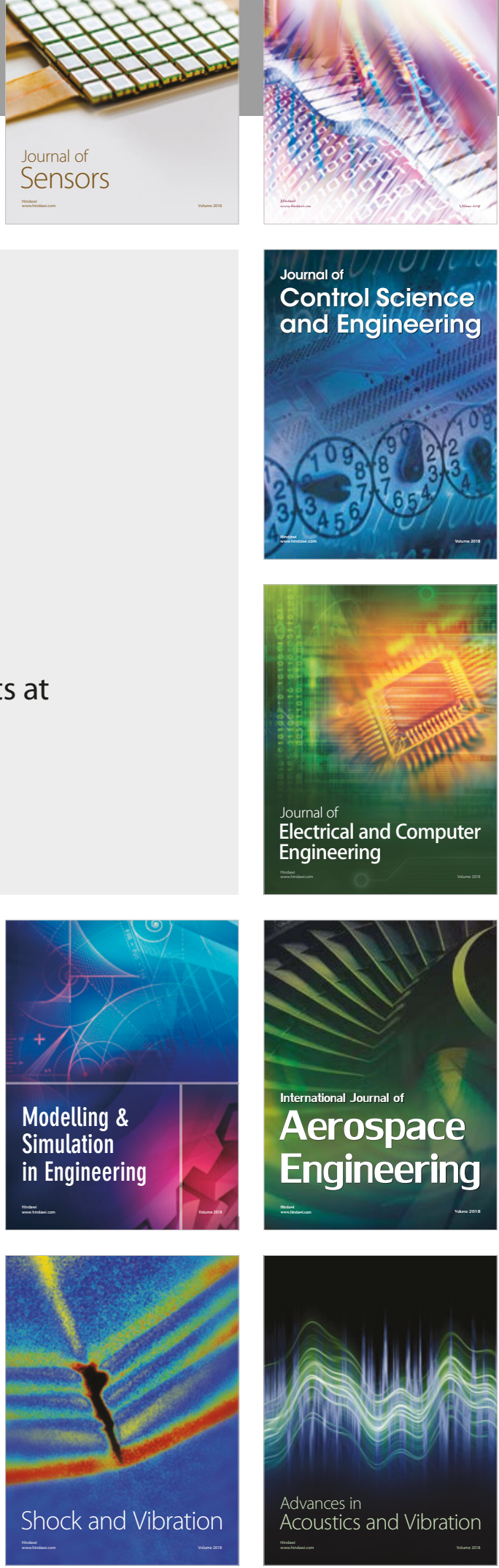